\title{
Criar e resolver problemas: habilidades para serem mobilizadas com licenciandos em Matemática
}

\section{Creating and solving problems: skills to be mobilized with ungraduated in Mathematics}

\author{
Patrícia Pujol Goulart Carpes \\ Universidade Federal do Pampa (UNIPAMPA), Campus Itaqui, RS, Brasil \\ (D) https://orcid.org/0000-0001-5206-8718, patigou23.carpes@gmail.com
}
Charles Quevedo Carpes
Universidade Federal do Pampa (UNIPAMPA), Campus Itaqui, RS, Brasil
(D) https://orcid.org/0000-0002-6070-3803, charles.carpes@gmail.com

\begin{abstract}
Informações do Artigo
Como citar este artigo

CARPES, Patrícia Pujol Goulart; CARPES,

Charles Quevedo. Criar e resolver problemas:

habilidades para serem mobilizadas com

licenciandos em Matemática. REMAT:

Revista Eletrônica da Matemática, Bento

Gonçalves, RS, v. 6, n. 2, p. e2008, 16 out.

2020. DOI:

https://doi.org/10.35819/remat2020v6i2id4224
\end{abstract}

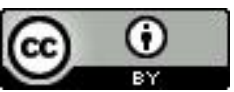

Histórico do Artigo

Submissão: 28 de maio de 2020.

Aceite: 22 de junho de 2020.

Palavras-chave

Criação e Resolução de Problemas

Criação de Problemas por Variação e por

Elaboração

Habilidades do Professor

\begin{abstract}
Resumo
O presente estudo tem o objetivo de apresentar e discutir uma proposta de ensino que mobilize as habilidades de criação e resolução de problemas com licenciandos em Matemática, com o objeto de conhecimento números racionais, a fim de apresentar ao professor de Matemática, possibilidades de desenvolvimento de algumas habilidades, referente a esse assunto, em sala de aula. Usa-se um roteiro adaptado da literatura para avaliar a capacidade de um grupo de licenciandos para criar problemas por variação e por elaboração. O procedimento de criar novos problemas e resolvê-los, propostos por colegas, foi desenvolvido em dois encontros presenciais com duração de duas horas para cada encontro. Com base nos registros dos participantes e nas observações dos pesquisadores, foi possível verificar que os licenciandos criam novos problemas por variação com modificações superficiais nos enunciados dos problemas iniciais. Além disso, pondera-se que a criação de problemas é uma estratégia importante para estimular a criatividade fortalecendo bom domínio de conceitos matemáticos e didáticos.
\end{abstract}

\section{Keywords}

Creation and Resolution of Problems

Creation of Problems by Variation and Elaboration

Teacher Skills

\begin{abstract}
The present study aims to show and discuss a teaching proposal that mobilizes the skills of creating and solving problems in Mathematics undergraduates, having as the object of knowledge the rational numbers, in order to envision the Mathematics teacher a possibility of how to develop in classroom such skills. A script adapted from the literature was used to assess the ability of a group of undergraduates to create problems by variation and elaboration. The procedure for creating new problems and their solution, proposed by colleagues, was developed over two face-toface two-hour meetings. Based on the participants' records and the researchers' observations, it was possible to verify that the students are able to create new problems with small variations from the initial problems. In addition, it is considered that the creation of problems is an important strategy to stimulate creativity and improve understanding of mathematical and didactic concepts.
\end{abstract}

\section{Introdução}

Diversos trabalhos apresentam discussões de professores e pesquisadores quanto ao modo tradicional de ensino não ser mais eficiente (MORAN, 2015). As figuras do professor como 
detentor do conhecimento e do aluno como um ser passivo ao qual é apresentado um estudo pronto e acabado têm sido questionadas. Nesse sentido, estudos têm proposto uma discussão sobre a importância do aluno no processo de ensino e aprendizagem (CARBONELL, 2002, MOREIRA, 2011). Ou seja, discute-se a relevância do aluno como ser ativo desse processo e propõe-se que o professor se torne um mediador entre o conhecimento e a aprendizagem.

Dessa forma, metodologias ativas, em que o aluno deixa de ser passivo, têm tomado o cenário como tendência na Educação Matemática. Metodologias de resolução de problemas, de investigação, de projetos, de modelagem formam o panorama atual e apontam para a mobilização de conhecimentos matemáticos por meio do desenvolvimento de estratégias, de argumentações, da análise de diferentes possibilidades de resoluções e de diferentes representações.

Porém, a partir da promulgação da Base Nacional Comum Curricular (BNCC) (BRASIL, 2017) com o caráter de lei, a compreensão de que o aluno deve ser ativo na sua aprendizagem deixou de ser tendência para se tornar fundamental no ambiente escolar. Nesse documento curricular, descreve-se as aprendizagens essenciais que os alunos devem desenvolver durante a etapa da Educação Básica por meio da mobilização de competências gerais e específicas de cada componente curricular.

Na Figura 1 apresenta-se uma ilustração do desenvolvimento de duas competências gerais previstas pela BNCC para o Ensino Fundamental e duas possíveis correspondências com as competências específicas da Matemática. Ambas podem ser alcançadas através da mobilização de habilidades operacionais previstas para alunos do sexto ano.

Figura 1 - O processo de desenvolver competências e a relação com a Matemática.

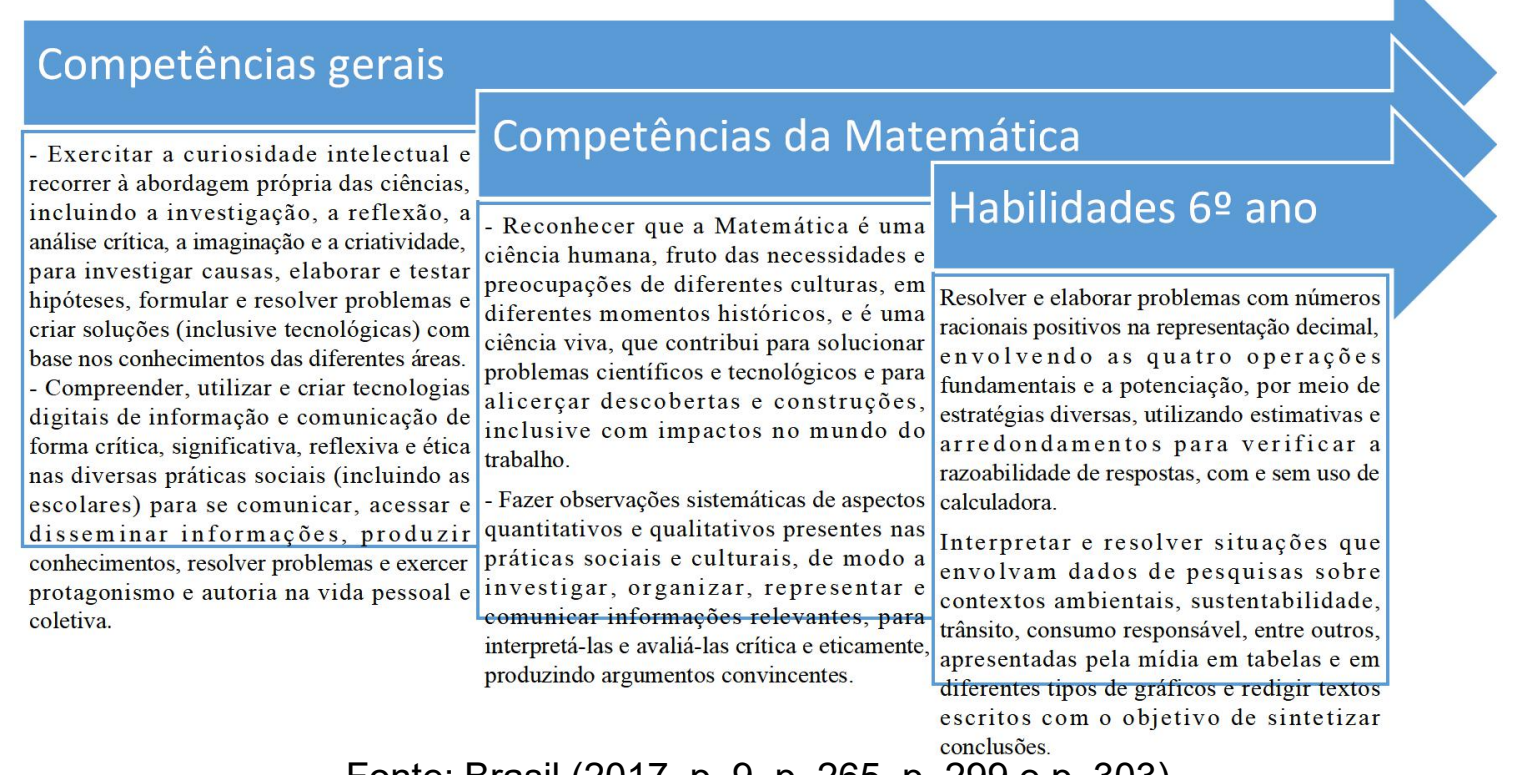

Fonte: Brasil (2017, p. 9, p. 265, p. 299 e p. 303).

Destaca-se que a habilidade de criar e resolver problemas (apresentada na Figura 1) é preconizada na BNCC para estudo do objeto de conhecimento "operações com números 
racionais", o que é uma diferença significativa nas propostas de ensino da maioria dos professores que seguem as metodologias ditas "tradicionais". Com isso, nota-se que a BNCC (BRASIL, 2017) não é apenas uma lista de objetos de conhecimento (conteúdos), mas uma proposta diferenciada no que ensinar e aprender. Subintende-se, assim, que uma aula simplesmente expositivadialogada não cumpre por si só a capacidade de desenvolver tais habilidades nos alunos.

Em se tratando do professor, a criação de problemas é uma parte fundamental de sua tarefa (JURADO; VARGAS, 2014). Desse modo, é necessário que os docentes desenvolvam a capacidade de criar problemas para poder orientar adequadamente a mobilização dessa habilidade em seus alunos.

Nesse sentido, este trabalho se objetiva a apresentar e discutir uma proposta de ensino que mobilize as habilidades de criação e resolução de problemas em licenciandos de Matemática, com os números racionais como objeto de conhecimento. Além disso, pretende-se oportunizar ao professor de Matemática a possiblidade de desenvolver, em sala de aula, as habilidades propostas.

\section{A criação e resolução de problemas}

No contexto atual, pensar em propor um estudo por resolução de problema ou modelagem é uma demanda desafiadora ao professor e ao aluno (BARBOSA, 2001, ALMEIDA; VERTUAN, 2011), visto que há certa obrigatoriedade em seguir um fluxo de conteúdos e cumprir as grades curriculares ou, muitas vezes, há resistência de professores e alunos quanto a uma forma diferenciada de desenvolver um conhecimento.

Nessa situação, a criação e resolução de problemas se apresenta como o problema dos problemas. Cria-se essa perspectiva, pois há uma maior demanda cognitiva para elaborar uma situação-problema, consequentemente, mais tempo dedicado ao desenvolvimento dessas habilidades. Assim, ao problematizar e investigar um problema surge um novo contexto em que o aluno é ativo em sua aprendizagem e o professor um mediador/facilitador.

Desta forma, questiona-se: O que deve ser entendido como criação de problemas? Os estudos do professor Jurado $(2013,2014 a)$ descrevem que a criação de um novo problema pode ser desenvolvida de duas formas distintas: $1^{\text {a }}$ a partir de um problema dado através da modificação de um, ou mais, elementos de tal problema, resultando num novo problema obtido por variação; $2^{\mathrm{a}}$ a partir de uma situação dada ou imaginada, denominada de elaboração de um problema.

Os autores Jurado e Vargas (2014) descrevem os quatro elementos fundamentais que constituem o enunciado de um problema, a saber:

A informação, a qual está constituída pelos dados quantitativos ou relacionais que estejam dados no problema.

O requerimento, o qual é o que se pede, que se examine ou que se conclua, que pode ser quantitativo ou qualitativo, incluindo gráficos e demonstrações. 
O contexto: é chamado "problema contextualizado" aquele que está relacionado com alguma situação real, com a vida cotidiana; no entanto, consideramos que o contexto também pode ser formal ou estritamente matemático. Nesse sentido, podemos afirmar que em um problema, o contexto pode ser intra-matemático ou extra-matemático. No primeiro caso, como seu nome indica o problema se circunscreve ao conhecimento de objetos matemáticos (por exemplo, falar o domínio de uma função [...]). No segundo caso, o problema está mais vinculado a uma situação real.

O elemento entorno matemático se refere aos conceitos matemáticos que intervém ou podem intervir para resolver o problema. Certamente isto é relativo, pois pode depender do caminho que se segue para resolver o problema. No marco da criação de problemas para a aprendizagem, o entorno matemático pode ser o ponto de partida para a criação de novos problemas, como "o tema a tratar". (p. 12-13, tradução dos autores).

A criação de problemas por variação pode ser o primeiro passo para uma proposta de ensino, pois ela modifica apenas um ou alguns dos quatros elementos fundamentais de um problema. Essa é uma maneira menos disruptiva em relação ao processo tradicional de ensino e aprendizagem da Matemática, ao passo que Jurado (2014b) indica que já é positivo criar problemas mediante variações ao problema dado (modificando informações quantitativas). Entretanto, se o aluno ${ }^{1}$ for capaz de realizar modificações qualitativas (trocas de objetos ou relações entre os objetos por exemplo) e quantitativas (trocas de dimensões de uma figura ou de um preço por exemplo) da informação, pode ser considerado que houve maior desenvolvimento de sua criatividade. Em ambos os casos, as modificações nas informações criam novos requerimentos (problemas).

A criação de problemas por elaboração é considerada um passo a mais na direção de aumentar a complexidade aos alunos. Nesse caso, capacidades como fluidez dos conhecimentos matemáticos e originalidade são necessárias para criar uma situação-problema. Jurado (2015) propõe que a elaboração de um problema pode ser um processo na forma livre e a partir de uma situação (dada pelo professor) ou a pedido específico (ênfase no conceito matemático ou didático).

Por uma situação dada, o contexto do problema se origina da situação, a informação é obtida pela seleção ou modificação da informação dada, o requerimento é uma consequência de relações lógicas e matemáticas apresentadas e o entorno matemático pode ser especificado pelo autor ou determina-se pelas diversas formas de resolver o problema.

A avaliação do pensamento criativo do aluno, ao elaborar seu problema, dada a partir de três fatores: a flexibilidade, a originalidade e a fluidez. Na criação de problemas, Jurado (2014a) aponta que a flexibilidade se manifesta, por variação, quando o sujeito é capaz de fazer modificações com amplitude, indo além de pequenas mudanças do problema inicial, no caminho para propor novas regras para a informação ou ao requerimento. A originalidade, via variação, se manifesta quando o sujeito propõe uma novidade ao problema dado e se distingue notoriamente de outras modificações realizadas ao mesmo problema por outros participantes. A fluidez se

\footnotetext{
${ }^{1} \mathrm{O}$ termo alunos neste caso se refere aos licenciandos do qual são os sujeitos do estudo.
} 
manifesta no sentido de criar vários problemas com ideias e propostas diferentes, a partir da situação e os problemas dados.

O processo de criação de problemas pode estimular o ambiente de ensino-aprendizagem e, consequentemente, trazer benefícios aos alunos e ao professor. Jurado e Vargas (2014) apontam que, aos alunos, é possível desenvolver sua criatividade fortalecendo a autoestima durante o processo de identificar e resolver problemas, formular perguntas, investigar, ver os aspectos matemáticos que existem ao seu redor, como também, estabelecer conexões com outros campos de conhecimento, ampliando sua visão da matemática e adquirindo uma sólida formação do componente curricular.

Os autores consideram que esse processo possibilita, aos professores, mobilizar competências, tais como: organizar problemas que reflitam iniciativas ou perguntas dos alunos que contribuam para esclarecer ou ampliar suas ideias, criar sequências de problemas de dificuldade gradual que leve a um problema particular importante, ter problemas adequados para aplicar as teorias sobre educação matemática (apoiadas na resolução de problemas), como também, melhorar a qualidade das avaliações.

Além disso, o professor tem um papel importante na criação de problemas em sala de aula. O professor deve ter competência em conhecimentos de matemática (específico) e didáticos para estimular adequadamente seus alunos à criatividade e potencializar a aprendizagem por meio da criação de problemas.

Diante de uma proposta desafiadora ao professor desenvolver a criação e resolução de um problema vinculado a um objeto de conhecimento com seus alunos, apresenta-se, na sequência, um roteiro adaptado de Canchanya (2015) a fim de vislumbrar possibilidades aos professores em propor essas habilidades aos seus alunos. Além disso, pretende-se desenvolver competências dos futuros professores a fim de estimular a capacidade de adaptar um problema a um público alvo, variar um problema para obter diferentes casos de uma situação e elaborar um problema a fim de compreender o objeto de conhecimento.

\section{Os procedimentos metodológicos}

Este estudo é de caráter qualitativo, visto que os dados são próprios dos sujeitos da pesquisa e do contexto sociocultural no qual estão inseridos por ocasião deste trabalho. Desse modo, como o pesquisador não possui um roteiro pré-determinado e rígido a ser seguido, então, torna-se passível, a ele, apontar limitações e potencialidades na sua análise.

Segundo Esteban (2010, p. 127)

[...] a pesquisa qualitativa é uma atividade sistemática orientada à compreensão em profundidade de fenômenos educativos e sociais, à transformação de práticas e cenários socioeducativos, à tomada de decisões e também ao descobrimento e desenvolvimento de um corpo organizado de conhecimentos. 
Dessa forma, a pesquisa qualitativa oportuniza alcançar dados descritivos que são produzidos em contato com o investigador na própria situação de estudo.

Utilizou-se dois encontros de formação docente, no primeiro semestre de 2019 perfizendo 4 horas de atividades presenciais, duas horas para cada encontro. Cabe destacar, que a formação foi constituída no total de seis encontros versando sobre números racionais. Os encontros de formação inicial tiveram a participação de 20 bolsistas do Programa Institucional de Bolsas de Iniciação à Docência (PIBID). Dessa forma, os participantes foram licenciandos de Matemática, de uma Instituição de Ensino Superior (IES) Pública do Estado do Rio Grande do Sul (RS), todos na primeira metade do curso.

O material de análise foi constituído pelos registros escritos dos participantes durante os encontros supracitados e dos apontamentos das observações realizadas da professora-formadora, primeira autora desse estudo, em seu diário de bordo. No Quadro 1, apresenta-se o roteiro para criação e resolução de problemas proposto aos licenciandos para os objetos números racionais.

Quadro 1 - Roteiro para a criação e resolução de problemas - parte 1.

\begin{tabular}{|c|c|c|}
\hline Situação & $\begin{array}{c}\text { Ações propostas aos } \\
\text { alunos }\end{array}$ & Objetivos \\
\hline \multirow{3}{*}{$\begin{array}{l}\text { Para o lanche da escola, Luana, Débora e Lucas } \\
\text { levaram uma barra de chocolate da mesma marca e } \\
\text { tamanho. Durante o recreio Luana dividiu igualmente } \\
\text { sua barra com uma amiga. Débora compartilhou } \\
\text { igualmente entre ela e suas três amigas. Lucas } \\
\text { percebeu que havia } 7 \text { colegas sem chocolate, dividiu } \\
\text { igualmente entre eles. Sabendo disso responda: } \\
\text { a) Com quem você preferiria dividir a barra de } \\
\text { chocolate? Por quê? } \\
\text { b) Se juntássemos as barras da Luana e Débora para } \\
\text { dividir igualmente entre elas e suas amigas, seria } \\
\text { possível que cada uma comesse } 30 \% \text { da barra? }\end{array}$} & $\begin{array}{l}\text { 1) Responder a } \\
\text { situação-problema } \\
\text { proposta. }\end{array}$ & $\begin{array}{l}\text { Compreender a } \\
\text { situação inicial } \\
\text { (6 min). }\end{array}$ \\
\hline & $\begin{array}{l}\text { 2) Apresentar e justificar } \\
\text { a solução determinada. }\end{array}$ & $\begin{array}{l}\text { Desenvolver o } \\
\text { raciocínio e a } \\
\text { argumentação da } \\
\text { solução determinada } \\
\text { (4 min). }\end{array}$ \\
\hline & $\begin{array}{l}\text { 3) Criação de um novo } \\
\text { problema modificando } \\
\text { alguns dados ou } \\
\text { perguntas do problema } \\
\text { inicial proposto. }\end{array}$ & $\begin{array}{l}\text { Imaginar e criar uma } \\
\text { situação-problema a } \\
\text { partir de um contexto } \\
\text { (5 min). }\end{array}$ \\
\hline
\end{tabular}

Fonte: Adaptado de Canchanya (2015, p. 54).

Inicialmente, o Quadro 1 ilustra os três primeiros passos elaborados por Canchanya (2015) para desenvolver a criação e resolução de problemas por alunos da Educação Básica. O roteiro é inspirado nas ideias de Jurado (2013) quanto à forma de criação de problemas: por variação ou por elaboração. Os passos 1 e 2 requerem que o aluno compreenda e resolva a situaçãoproblema dada. O passo 3 requer a criação de um problema por variação, ou seja, alterando um ou mais elementos da situação inicial dada.

Nos encontros de formação, foi proposto que os alunos se organizassem em duplas para desenvolverem a parte 1 do roteiro. Na terceira coluna do Quadro 1, há uma sugestão/expectativa de tempo para a realização da atividade. Cabe salientar, que este tempo estimado pela escola para a realização da atividade. Ciente que dado o encaminhamento do professor, há a possibilidade de outros espaços e tempo para mobilizar as habilidades de criar e resolver problemas. Ao término dos três passos, a formadora recolheu as atividades, no intuito de encaminhar a parte 2 do roteiro, ilustrada no Quadro 2. 
Quadro 2 - Roteiro para a criação e resolução de problemas - parte 2.

\begin{tabular}{|l|l|}
\hline \multicolumn{1}{|c|}{ Passos do roteiro } & \multicolumn{1}{|c|}{ Objetivo } \\
\hline $\begin{array}{l}\text { 4) Cada dupla deve solucionar o problema criado (do } \\
\text { colega). }\end{array}$ & $\begin{array}{l}\text { Verificar se o problema foi corretamente } \\
\text { elaborado, com as informações necessárias ou } \\
\text { com dados desnecessários (5 min). }\end{array}$ \\
\hline $\begin{array}{l}\text { 5) Alguns estudantes explicam oralmente como } \\
\text { determinaram a solução do novo problema. Comente } \\
\text { sobre a estratégia usada, se havia outro registro. }\end{array}$ & $\begin{array}{l}\text { Desenvolver a argumentação e estratégia de } \\
\text { solução (6 min). }\end{array}$ \\
\hline $\begin{array}{l}\text { 6) Questionar os alunos sobre outras possibilidades que } \\
\text { poderiam ser exploradas desde a situação inicial. }\end{array}$ & $\begin{array}{l}\text { Buscar situações correlatas às dadas como } \\
\text { número de pessoas ou barras de chocolate por } \\
\text { exemplo (4 min). }\end{array}$ \\
\hline
\end{tabular}

Fonte: Adaptado de Canchanya (2015, p. 54).

O passo 4, do Quadro 2, foi encaminhado a outra dupla para resolução. O objetivo era de verificar se a construção do problema e se as informações dispostas eram pertinentes e necessárias para resolução do problema criado. O passo 5 propõe que os alunos argumentem de forma escrita e oral sua compreensão referente ao problema criado e as diferentes possibilidades de resolver/interpretar o problema. O passo 6 extrapola a ideia do passo 5 no sentido de vislumbrar outras possibilidades, ainda não consideradas do problema, com o grande grupo de alunos. E, finalmente, a parte 3 do roteiro, apresentada no Quadro 3, após os alunos terem compreendido a situação inicial e suas variações, propõe-se a criação de problemas por elaboração.

Quadro 3 - Roteiro para a criação e resolução de problemas - parte 3.

\section{Passos do roteiro}

7) Criar um novo problema relacionado a situação inicial e que na solução desse problema seja trabalhado um conceito matemático específico (soma com racionais por exemplo).

8) Cada aluno deve responder ao problema criado pelo colega.

9) Peça que cada aluno compartilhe oralmente com a turma o problema criado e, para alguns alunos, os encaminhamentos da solução desses problemas.

\section{Objetivo}

Criar um problema para explorar um conhecimento específico (6 min).

Verificar se seu problema foi corretamente elaborado, com as informações necessárias ou com dados desnecessários (6 min).

Desenvolver a capacidade de argumentação e estratégia de solução (10 min).

$$
\text { Fonte: Adaptado de Canchanya (2015, p. 54). }
$$

O passo 7, do Quadro 3, propõe a criação de problemas por elaboração no caso de pedido específico, sendo eles os diferentes significados dos números racionais, suas representações ou operações. Cada dupla recebeu um pedido específico para criar um problema. Após, no passo 8, novamente, a formadora recolheu a atividade e a encaminhou a uma outra dupla para resolução, finalizando com os comentários/argumentações sobre a criação e resolução do problema criado com o grande grupo de alunos.

Na linha de pensamento de Guilford (1967) e Torrance (1967), Jurado (2013) pontua que o pensamento criativo está baseado em fatores fundamentais. A análise da habilidade de criação de problemas permite observar a flexibilidade manifestada, isto é, modificações com amplitude à 
situação inicial dada; a originalidade quando se propõe uma novidade ao problema dado e; a fluidez quando se cria mais de um problema com ideias diferentes do problema dado.

Os registros dos licenciandos, referente ao roteiro, foram analisados conforme apontam Jurado $(2013,2014 a)$ e Canchanya (2015) quanto à capacidade de criação a partir da situação inicial, por variação, considerando a clareza, a flexibilidade, a originalidade e a fluidez, assim como, também, dos conhecimentos matemáticos mobilizados na criação e resolução dos problemas. Esses registros serão analisados na próxima seção.

\section{Análise e discussões dos registros dos licenciandos}

A análise dos dados apresentada nesta seção é constituída pelo material escrito dos licenciandos em Matemática durante os encontros de formação e observações da formadora. Nesse sentido, cabe destacar que os participantes desenvolveram o roteiro em duplas a fim de aprimorar seus conhecimentos didático-matemáticos referente ao objeto número racional.

Os conhecimentos específicos do professor são, neste caso, a criação de problemas por variação propõe a ideia que o professor é competente para variar uma situação-problema e conseguir abordar diferentes casos de uma mesma situação. Ou, ainda, a criação de problemas por elaboração, pode ser vista como um caso mais refinado, com maior demanda cognitiva ao aluno ou, então, considerada como a competência do professor em conseguir elaborar um problema, dentro da realidade do aluno, que permita desenvolver em específico um objeto de conhecimento.

O roteiro inicia com uma situação-problema a fim de que os participantes partam de uma situação para a criação de uma nova (por variação). A atividade do Quadro 4 ilustra uma situação que pode explorar os significados de parte/todo ou quociente do número racional, assim como suas possíveis representações (fração, decimal ou porcentagem) dependendo do procedimento de resolução adotado pelos licenciandos.

\section{Quadro 4 - Situação-problema inicial.}

Para o lanche da escola, Luana, Débora e Lucas levaram uma barra de chocolate da mesma marca e tamanho. Durante o recreio, Luana dividiu igualmente sua barra com uma amiga. Débora compartilhou igualmente entre ela e suas três amigas. Lucas percebeu que havia 7 colegas sem chocolate, dividiu-o igualmente entre eles. Sabendo disso responda:

a) Com quem você preferiria dividir a barra de chocolate? Por quê?

b) Se juntássemos as barras da Luana e Débora para dividir igualmente entre elas e suas amigas, seria possível que cada uma comesse $30 \%$ da barra?

\section{Fonte: Dados da pesquisa (2019).}

A resposta do item (a), do Quadro 4, trouxe dúvidas aos participantes. O termo "preferiria dividir" é pessoal, logo não há uma resposta certa/única, é um problema aberto. A expressão pode ensejar a preferência, pois os alunos que gostam de chocolate preferiram dividir com a Luana (receberiam a metade da barra), os que não gostam de chocolate preferiram dividir com as outras 
pessoas. Os procedimentos de resolução estiveram centrados na representação pictórica da barra de chocolate, ilustrando as partes que cada um receberia por meio do significado parte/todo, com registro fracionário e porcentagem.

O item (b) foi resolvido predominantemente pelo significado de quociente $\frac{2 \text { barras }}{6 \text { amigas }}=\frac{1}{3} \approx$ $33 \%$, obtendo o resultado no qual cada colega comeria mais que $30 \%$ da barra. Outros adotaram o significado parte/todo, dividiram cada barra em três partes iguais, somando 6 partes com as duas barras, logo cada colega comeria um terço da barra. Cabe mencionar, que duas duplas (20\%) erraram o item (a) e duas duplas (20\%) erram o item (b), sendo que uma dupla errou concomitantemente os dois itens, ou seja, não souberam interpretar a questão.

O passo 3 do roteiro, ilustrado no Quadro 1, após os participantes terem compreendido e discutido entre a dupla a interpretação e possíveis procedimentos de resolução, foi proposto que eles criassem um novo problema por variação, ou seja, alterando um (ou mais) dos quatro elementos do enunciado. O Quadro 5 apresenta os problemas criados que há semelhanças no requerimento do problema, com poucas alterações.

Quadro 5 - Problemas criados pelos licenciandos por variação com requerimentos semelhantes. $\mathrm{Na}$ situação do problema, se juntássemos todos os chocolates e dividíssemos igualmente, quanto cada pessoa comeria? (dupla C e K)

Se juntássemos as 3 barras de Luana, Débora e Lucas e dividíssemos igualmente entre seus amigos, quantos por cento cada um comeria? E se a Débora dividisse o chocolate com apenas duas amigas, qual seria a porcentagem do pedaço? (dupla F)

Se juntássemos as barras de Luana, Débora e Lucas e dividir igualmente entre eles e seus amigos, qual a porcentagem da barra que cada um comeria? (dupla D)

Para o lanche da escola Luana, Débora e Lucas ficaram responsáveis em levar o chocolate para toda a sua turma, que contém 20 pessoas. Levaram, então, 3 barras, quanto cada colega pode comer? (dupla A)

Fonte: Dados da pesquisa (2019).

A criação de problemas por variação das duplas do Quadro 5, convergem para o mesmo requerimento de unir a quantidade de barras e dividir entre a quantidade de amigos do problema inicial. O fator clareza dos problemas, a princípio, estavam bem construídos e com uma pergunta objetiva. Apenas a dupla A não especificou se a divisão era igualitária entre todos, o que pode gerar dúvida a quem responde o problema.

O fator flexibilidade ao criar os problemas do Quadro 5, mostra que não foram realizadas modificações amplas ao problema inicial, principalmente ao requerimento (parte do chocolate que cada um receberia). Há a alteração de informação da dupla A (20 pessoas) e tipo de registro (para porcentagem) das duplas F e D. Metade do grupo (5 duplas) optaram em criar este requerimento ao problema. Quando aberto ao grande grupo (passo 5), as duplas comentaram que visualizaram uma questão óbvia em querer dividir igualmente entre todos.

O fator originalidade ficou prejudicado, pois era uma questão óbvia (porém condizente) em distribuir os chocolates igualmente. Nota-se que as modificações ao problema inicial ficaram 
centradas em considerar o total de pessoas e dividir igualmente o chocolate. Ao mesmo passo, o fator fluidez é pouco manifestado, pois não se criou problemas com ideias diferentes ao problema dado (ideia de dividir o chocolate). A dupla $\mathrm{F}$ criou dois problemas, mas que não se afastam da proposta do problema dado.

A outra metade de participantes ao responderem o passo 3 do roteiro, criaram problemas alterando vários elementos da situação inicial conforme apresentado no Quadro 6.

Quadro 6 - Problemas criados por variação alterando vários elementos do problema inicial. Para o lanche da Escola, Luana, Débora e Lucas juntos levaram 18 barras de chocolate. Sabe-se que Lucas levou 3 e Luana levou $\frac{1}{3}$ a mais que Lucas. Quantas barras Luana e Débora levaram? (dupla J)

Para o lanche da escola, José, Pedro e Ana compraram uma garrafa de refrigerante cada para dividir com seus amigos. José dividiu com 4 amigos, Pedro com 3 e Ana com apenas uma amiga. A) Você prefere dividir o refrigerante com o Pedro ou com o José? Por quê? B) Se juntassem as garrafas de Pedro e José, quantos ml cada um (incluindo os amigos) receberiam? (dupla I)

Para o lanche da escola Luana, Débora e Lucas levaram um bolo de chocolate cada um do mesmo tamanho. Luana dividiu com sua amiga $50 \%$ do bolo, Débora dividiu $75 \%$ do seu bolo com suas 3 amigas e Lucas dividiu $30 \%$ com 3 amigos. Com quem você preferiria dividir o bolo? (dupla $\mathrm{H}$ )

Para o lanche da escola Luana, Débora e Lucas levaram, cada um, uma maçã. Durante o intervalo Luana dividiu com uma amiga. Débora dividiu entre 5 amigas e Lucas percebeu e dividiu em 7 amigos. A) Quem ficou com a menor parte? B) Com quem você preferiria dividir? (dupla E)

Qual a representação geométrica que Débora comeu? Se juntássemos as barras de Débora e Lucas e dividíssemos entre eles e seus amigos, cada um conseguiria comer $18 \%$ ? (dupla B)

Fonte: Dados da pesquisa (2019).

O problema criado pela dupla $\mathrm{J}$ modifica a quantidade de barras de chocolate e pode abordar um significado ainda não explorado do número racional, o operador $\left(\frac{1}{3} .3\right)$. Além disso, altera o requerimento do problema. Logo, se identifica a flexibilidade e originalidade do problema criado.

A dupla I criou um problema que se assemelha ao dado inicialmente. Entretanto, deixou de esclarecer se as divisões entre os amigos seriam igualitárias e se as garrafas tinham o mesmo volume de refrigerante o que causa dificuldade na compreensão do problema. Contudo, durante o passo 5 do roteiro, a dupla que respondeu o problema, mencionou que o item (a) poderia ser uma questão oportuna aos alunos, para estudar a concepção de unidade (todo). A questão não deixa claro qual é o todo para fazer a comparação entre a bebida do José e do Pedro. Assim, seria possível levantar hipóteses para o volume de cada garrafa e fazer o estudo de quem receberia mais bebida. Entretanto, a dupla que formulou a questão não pensou dessa maneira, a ideia inicial seria que, nas três garrafas, cada uma delas contivesse o mesmo volume.

O problema criado pela dupla $\mathrm{H}$ tem o mesmo requerimento da situação inicial, logo é um fator para a fluidez ser considerada limitada. Porém, as informações do enunciado se alteraram amplamente. Mostrando uma maior flexibilidade em fazer modificações quantitativas e qualitativas. 
Como também, a originalidade se manifesta, pois, os sujeitos não dividiram toda a unidade, apenas um percentual.

Os problemas criados pelas duplas E e B são limitadas nos fatores flexibilidade e originalidade. No problema da dupla $\mathrm{E}$, há uma alteração quantitativa no número de pessoas com as quais Débora dividiu a unidade. Os requerimentos dos dois problemas são válidos num processo de compreensão do objeto de estudo, pois identificam quem ficou com a menor parte, une a quantidade de duas pessoas (Débora e Lucas) e trabalha com outra porcentagem, diferenciando-se, assim, da situação inicial. O fator fluidez ficou prejudicado, pois as modificações ao problema inicial foram pequenas, variando com casos similares, sem introdução de um requerimento para estudo/problematização de outro objeto matemático.

O passo 7 do roteiro, apresentado no Quadro 3, propõe a criação de problemas por elaboração a fim de desenvolver a compreensão de um objeto matemático em específico. Dessa maneira, pontua-se que a análise das criações de problemas pelos licenciandos se dá a partir do alcance/exploração dos conhecimentos matemáticos propostos, se as informações e requerimento são coerentes, claros e se a resolução pelos colegas foi possível atingir o objetivo proposto pelo professor ao objeto de estudo.

O Quadro 7 apresenta os problemas criados pelos licenciandos e o procedimento de resolução de uma dupla de colegas no intuito de facilitar a visualização pelo leitor da exploração do objeto de conhecimento proposto. Ressalta-se que a representação do número racional não foi fixada, assim poderia ser adotado no problema o registro na forma de fração, decimal, porcentagem ou pictórica.

A elaboração de problemas para o objeto de conhecimento unidade (decompor e recompor a grandeza seja contínua ou discreta) foi desenvolvida por duas duplas. A dupla D trabalhou esse objeto com a representação de porcentagem do número racional. O problema está bem formulado, com requerimentos objetivos e nota-se que na sua solução a dupla de colegas empregou o conceito de unidade, ao se referir ao $100 \%$ dos frios. Nota-se, também, que a dupla ao elaborar o problema afastou-se do contexto da situação inicial, mas permaneceu com a ideia de dividir o todo em partes iguais. Já a dupla $B$, permaneceu apenas com os nomes dos sujeitos do problema inicial, alterando o contexto, a grandeza e as quantidades. A solução dada pela dupla E explora o conceito de unidade, entretanto não determina a resposta esperada, número de figurinhas, apenas um percentual aproximado em relação ao todo $(100 \%-83 \%=17 \%)$.

O problema elaborado pela dupla $\mathrm{F}$, para explorar o objeto valor posicional (compreensão da ordenação, comparação e densidade dos números racionais), foi dado por uma linha que representa a reta numérica, o que sugere registrar o valor posicional dos corredores no instante 15 segundos após a largada. A dupla buscou transitar em diferentes registros do número racional. No entanto, a dupla $\mathrm{H}$ mencionou que não compreendeu o problema e apresentou um erro ao retirar os dados do problema (Luana havia percorrido $45 \%$ da prova). Percebe-se que a dupla $\mathrm{H}$, 
inicialmente buscou os registros todos em porcentagem, o que poderia facilitar a comparação entre os números, mas ficaram limitados por não interpretar o problema e/ou não compreender o objeto valor posicional/comparação.

Quadro 7 - Criação e resolução de problemas por elaboração.

\begin{tabular}{|c|c|c|}
\hline $\begin{array}{c}\text { Objeto de } \\
\text { conhecimento }\end{array}$ & Criação de problema por elaboração & Resolução do problema \\
\hline Unidade & $\begin{array}{l}\text { No natal foi comprado um cento de frios para } \\
\text { uma confraternização de um grupo de } 7 \\
\text { amigos. Sabendo-se que o cento de frios custa } \\
\text { R } \$ 95, \text { o valor foi dividido igualmente entre eles. } \\
\text { Quanto cada amigo pagou? Sabendo que } 3 \\
\text { amigos comeram } 14 \% \text { dos frios cada um, } \\
\text { outros } 2 \text { amigos } 20 \% \text { dos frios cada um e os } 2 \\
\text { restantes comeram } 9 \text { frios cada um. Quantos } \\
\text { frios cada um dos } 7 \text { amigos comeu? (dupla D) }\end{array}$ & $\begin{array}{l}\text { Cada amigo pagou aproximadamente } \\
\mathrm{R} \$ 13,57 \text {. } \\
\text { Os amigos que comeram } 14 \% \text { dos frios } \\
\text { cada, comerem } 42 \text { frios, } 14 \text { cada um. } \\
\text { Os que comeram } 20 \% \text { cada, comeram } \\
40 \% \text { de frios, } 20 \text { cada um. Os amigos } \\
\text { que comeram } 9 \text { frios, comeram } 18 \% \\
\text { dos frios, } 9 \% \text { cada um. Totalizando } \\
\text { assim } 100 \% \text { dos frios. (dupla A) }\end{array}$ \\
\hline $\begin{array}{c}\text { Valor } \\
\text { posicional }\end{array}$ & $\begin{array}{l}\text { Em uma corrida de } 1 \mathrm{~km} \text {, Luana, Débora e } \\
\text { Lucas competem para ver quem completa a } \\
\text { corrida em menos tempo. Nos } 15 \text { primeiros } \\
\text { segundos, Débora alcançou } 20 \% \text { do percurso } \\
\text { inteiro enquanto estava Lucas a } \frac{1}{4} \text { do ponto de } \\
\text { partida e Luana estava à } 55 \% \text { da chegada. } \\
\text { Quantos km cada um percorreu nos } 15 \\
\text { primeiros segundos? (dupla F) } \\
\text { Partida } 0 \text { 1 Chegada }\end{array}$ & $\begin{array}{l}\text { Débora }=20 \% \\
\text { Lucas }=25 \% \\
\text { Luana }=55 \% \\
\text { Não entendemos. } \\
\text { (dupla } \mathrm{H} \text { ) }\end{array}$ \\
\hline $\begin{array}{l}\text { Significado } \\
\text { operador }\end{array}$ & $\begin{array}{l}\text { Para o lanche da escola, Débora e Luana } \\
\text { levaram um bolo, repartiram o bolo em } 16 \\
\text { fatias iguais. } 50 \% \text { do bolo foi repartido } \\
\text { igualmente entre os meninos e os outros } 50 \% \\
\text { foi repartido igualmente entre as meninas. } \\
\text { Sabendo que essa turma tem } 20 \text { alunos, sendo } \\
8 \text { meninos, qual a porcentagem de bolo cada } \\
\text { menina recebeu? (dupla C) }\end{array}$ & 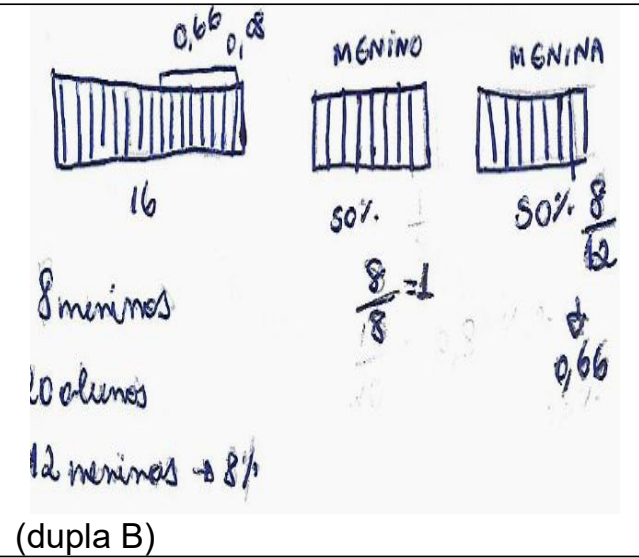 \\
\hline Unidade & $\begin{array}{l}\text { Luana, Débora e Lucas querem completar um } \\
\text { álbum de figurinhas. Luana contribuiu com } \frac{1}{6} \\
\text { das figurinhas, enquanto Débora contribuiu } \\
\text { com } \frac{2}{3} \text {. Com quantas figurinhas Lucas terá que } \\
\text { contribuir para completar o álbum? (dupla B) }\end{array}$ & $\begin{array}{l}\text { Luana }-\frac{1}{6}=0,1666 \ldots \\
\text { Débora }-\frac{2}{3}=0,666 \ldots \\
\text { Somando }=\frac{5}{6}=0,833 \ldots=83 \% \\
100 \%-83 \%=17 \% . \\
\text { (dupla } \mathrm{E})\end{array}$ \\
\hline $\begin{array}{l}\text { Significado } \\
\text { parte/todo }\end{array}$ & $\begin{array}{l}\text { No mercado tem um pote de manteiga de } 1 \mathrm{~kg} \\
\text { por } \mathrm{R} \$ 23 . \text { Na mesma prateleira tem outro pote } \\
\text { da mesma marca } \frac{1}{4} \text { menor com valor de } \mathrm{R} \$ 12 \text {. } \\
\text { Quero fazer um bolo e preciso de } 850 \mathrm{~g} \text {. Na sua } \\
\text { opinião, qual dos potes seria mais vantajoso, } \\
\text { referindo-se ao custo/quatnidade? (dupla I) }\end{array}$ & $\begin{array}{l}\text { Na nossa opinião seria mais vantajoso } \\
\text { comprar } 2 \text { potes de } R \$ 12 \text {, pois vou } \\
\text { comprar } 1,5 \mathrm{~kg} \text { por } R \$ 24 \text {, ainda ganho } 2 \\
\text { potes e tudo isso por apenas } R \$ 1 \text { a } \\
\text { mais. (dupla } K \text { ) }\end{array}$ \\
\hline $\begin{array}{l}\text { Operação de } \\
\text { subtração }\end{array}$ & $\begin{array}{l}\text { Luana levou à escola uma barra de chocolate } \\
\text { de } 96 \mathrm{~g} \text { e deu } \frac{1}{3} \text { da barra. Chegando a escola } \\
\text { comeu a metade do que sobrou e deu o } \\
\text { restante para Débora. Quantos gramas Débora } \\
\text { recebeu? (dupla K) }\end{array}$ & $\begin{array}{l}1 \text { barra ------ 96g } \\
\frac{1}{3} \text { de } 96 \mathrm{~g}=32 \mathrm{~g} \quad 96-32=64 \mathrm{~g} \\
\text { Comeu } \frac{64}{2}=32 \mathrm{~g} \quad 64-32=32 \mathrm{~g} \\
\text { Débora recebeu } 32 \mathrm{~g} . \\
\text { (dupla C) }\end{array}$ \\
\hline
\end{tabular}

Fonte: Dados da pesquisa (2019). 
O significado parte/todo (apresentado sob a forma $\frac{1}{n}$ em que esta fração representa uma ou mais partes da unidade que foi dividida em parte iguais) foi explorado pela dupla I. O problema sugere o emprego do parte/todo ao calcular um quarto de um quilo (poderia ser adotado também o significado de operador). Pela resposta da dupla, não é possível afirmar que houve o emprego de tal significado. E, ainda, cabe mencionar que a resposta é particular, ou seja, poderia ser tenho apenas $R \$ 23$, não posso comprar a outra opção ou não é vantagem ter uma sobra grande de um produto que pouco utilizo, por exemplo.

O problema elaborado pela dupla $\mathrm{K}$ para o objeto subtração de números racionais remetenos a situação inicial, com uma flexibilidade bem maior, pois trabalha com o significado de operador, quociente e de não operar sempre sobre a quantidade inicial (mas com a sobra). O enunciado do problema elaborado inadequadamente (levou uma barra de chocolate à escola, porém chegando na escola tinha apenas dois terços da barra). No entanto, a dupla $C$ resolveu o problema segundo a expectativa da dupla que o criou. A subtração ocorreu com números inteiros (que são racionais também). Nota-se que o problema poderia ter se tornado mais complexo se as divisões não fossem exata, por exemplo.

O problema elaborado pela dupla $\mathrm{C}$, para o significado de operador, foi parcialmente compreendido pela dupla $B$, que o respondeu. Os dados retirados do enunciado são condizentes, mas não respondem ao problema. O percentual que cada menino recebeu foi a razão $\frac{1}{16}(6,25 \%$ do bolo para cada menino). Já as meninas receberam $\frac{8}{12} \cdot \frac{1}{16} \approx 0,04$ (aproximadamente $4 \%$ do bolo cada uma). O emprego do significado de operador pode se dar fazendo a interpretação de que cada menina comeu dois terços de uma fatia, o que representa $4 \%$ do bolo inteiro (16 fatias).

\section{Considerações finais}

Neste estudo, buscou-se discutir uma proposta de ensino que desenvolvesse as habilidades de criação e resolução de problemas com licenciandos em Matemática para o objeto número racional, por meio de um roteiro adaptado de Canchanya (2015), a fim de vislumbrar uma possibilidade ao professor de Matemática, de como desenvolver essas habilidades em sala de aula.

Vale ressaltar que o roteiro é uma proposta para empregar a criação e resolução de problemas por variação e por elaboração juntos. Entretanto, de acordo com os objetivos do professor, ele pode ser desenvolvido parcialmente. Nota-se que o desenvolvimento integral do roteiro demanda tempo. Nesse sentido, o professor pode optar, por exemplo, pela variação e estudar as diferentes possibilidades de uma situação-problema no ambiente de sala de aula ou fora.

Os problemas criados pelos licenciandos, por meio do roteiro proposto, são fechados, ou seja, busca-se uma solução única por meio de um algoritmo. Há pouco espaço para a criação de 
estratégias para determinar uma solução por exemplo. Houve o problema criado pela dupla I, quadro 6 , que não mencionou o todo (volume), logo poderia ser feito um estudo dos possíveis casos que uma pessoa poderia receber mais refrigerante que a outra. Desse modo, não tendo uma resposta única, sendo, assim, uma questão mais rica em conhecimentos mobilizados.

Vale destacar, que as metodologias ativas como a resolução de problemas e as habilidades de criação e resolução de problemas estão cada vez mais sendo inseridas nos currículos de formação dos professores de Matemática. Neste estudo, houve uma prática com um grupo de licenciandos, num período preestabelecido de tempo, mas percebe-se o potencial criado para discutir, compreender e exercitar o que é um problema e como criá-lo.

Além da criação de problemas, percebe-se dificuldades dos licenciandos em resolver o problema criado pelo colega seja pela sua falta de conhecimento e/ou não interpretação correta da situação. Embora os problemas criados fossem simples, os fatores interpretação/abstração e retirada dos dados do enunciado apontam para a complexidade envolvida nestas ações. Alia-se a esse fato a pouca atenção dos licenciandos ao justificar/explicar sua resposta/compreensão (passos 5 e 9 do roteiro). Como também, alia-se a essas dificuldades uma possível falta de hábito de leitura, interpretação e discussão de textos.

Em ambos os casos, a criação e a resolução de problemas demonstram uma necessidade de trabalho/estudo na formação dos professores. É essencial que os docentes desenvolvam a capacidade de criar problemas para orientar adequadamente o desenvolvimento das habilidades de seus alunos (JURADO; VARGAS, 2014). Ao passo que, neste estudo, oferta-se uma possibilidade de mobilização para tais habilidades faz-se necessário tomar medidas para que a leitura, a interpretação, a discussão de materiais científicos façam parte do processo de formação dos professores.

A criação de problemas matemáticos requer, no mínimo, conhecimento e prática. Necessita-se pensar e repensar sobre o problema criado quanto às possíveis interpretações, procedimentos de resolução ou conhecimentos mobilizados. Além disso, Jurado e Vargas (2014) acrescentam que é um desafio ao próprio professor criar sequências de atividades e problemas adequados para realidade presenciada, assim como, estimular seus alunos não apenas a resolver problemas, mas, também, a criar seus próprios problemas. Além disso,

O processo de criar problemas representa uma das formas autênticas de investigação matemática, que adequadamente implementada em atividades de classe, tem o potencial de ir além das limitações dos problemas verbais, pelo menos como são tipicamente tratados. Impulsionar a criação de problemas é uma das formas de ganhar o desenvolvimento de diferentes potencialidades dos estudantes e de estimular uma maior flexibilidade mental. (BONOTTO, 2013, p. 53, apud JURADO; VARGAS, 2014, tradução dos autores).

Por fim, menciona-se que os encontros de formação oportunizaram, aos participantes, reflexões acerca das possibilidades de criar problemas por variação ou elaboração no ambiente de sala visando mobilizar conhecimentos matemáticos. Além disso, os próprios licenciandos reconhecem a necessidade de estudar, desde a formação inicial, com a perspectiva de explorar 
competências fundamentais do professor: criar e resolver problemas ligados a realidade dos alunos/escola a fim de motivá-los aos estudos e, de forma mais ampla, apresentar-lhes como a Matemática pode ser explorada em diversas situações do cotidiano.

\section{Referências}

ALMEIDA, L. M. W de; VERTUAN, R. E. Discussões sobre "como fazer" modelagem matemática na sala de aula. In: ALMEIDA, L. M. W. de; ARAÚJO, J. de L.; BISOGNIN, E. (Orgs.). Práticas de modelagem matemática: relatos de experiências e propostas pedagógicas. Londrina, PR: Eduel, 2011. p. 19-43.

BARBOSA, J. C. Modelagem na Educação Matemática: contribuições para o debate teórico. In: REUNIÃO ANUAL DA ANPED, 24, 2001, Caxambu. Anais... Caxambu: ANPED, 2001. Disponível em:

http://www.educadores.diaadia.pr.gov.br/arquivos/File/2010/artigos teses/MATEMATICA/Artigo B arbosa.pdf. Acesso em: 11 out. 2020.

BRASIL. Ministério da Educação. Base Nacional Comum Curricular. 2017. Brasília: MEC, 2017. Disponível em: http://basenacionalcomum.mec.gov.br/images/BNCC 20dez site.pdf. Acesso em: 24 jan. 2018.

CANCHANYA, J. F. C. Análisis de problemas de adición, sustracción y multiplicación de expresiones decimales, creados por estudiantes del sexto grado de primaria en una experiencia didáctica. 2015, 128f.Tese (Doutorado em Ensino da Matemática) - Pontificia Universidad Católica del Perú, Escuela de Posgrado, Perú, 2015. Disponível em: http://tesis.pucp.edu.pe/repositorio/bitstream/handle/20.500.12404/6754/CARDENAS CANCHAN YA JORGE ANALISIS.pdf?sequence=1\&isAllowed=y. Acesso em: 11 out. 2020.

CARBONELL, J. A aventura de inovar: a mudança na escola. Trad.: MURAD, Fátima. Porto Alegre: Artmed, 2002.

ESTEBAN, M. P. S. Pesquisa qualitativa em educação: fundamentos e tradições. Trad.: CABRERA, Miguel. Porto Alegre: AMGH, 2010.

Guilford, J. P. Creativity: Yesterday, today, and tomorrow. Journal of Creative Behavior. v. 1,n. 1, 1967, p. 3-14 DOI: https://doi.org/10.1002/j.2162-6057.1967.tb00002.x.

JURADO, Uldarico Malaspina. Variaciones de un problema. El caso de un problema de R. Douady. Revista Iberoamericana de Educación Matemática, v. 34, p. 141-149, jun. 2013. Disponível em: http://www.fisem.org/www/union/revistas/2013/34/archivo13.pdf. Acesso em: 12 jun. 2019.

JURADO, Uldarico Malaspina. Papiroflexia y elementos para construir indicadores sobre creación de problemas. Revista Iberoamericana de Educación Matemática. v. 38, p. 135- 141. 2014a. Disponível em: http://www.fisem.org/www/union/revistas/2014/38/archivo12.pdf. Acesso em: 12 jun. 2019.

JURADO, Uldarico Malaspina. Flexibilidad, originalidad y fluidez en la variación de problemas. Revista Iberoamericana de Educación Matemática. v. 39, p. 135-140. 2014b. Disponível em: http://www.fisem.org/www/union/revistas/2014/39/archivo12.pdf. Acesso em: 12 jun. 2019.

JURADO, Uldarico Malaspina. Creación de problemas: sus potencialidades en la enseñanza y aprendizaje de las matemáticas. Cuadernos de Investigación y Formación en Educación Matemática, Costa Rica, ano 11, n. 15, p. 321-331, 2016. Disponível em: https://revistas.ucr.ac.cr/index.php/cifem/article/view/23946. Acesso em: 11 out. 2020. 
JURADO, Uldarico Malaspina; VARGAS, Estela Vallejo. Creación de problemas en la docencia e investigación. In: JURADO, Uldarico Malaspina. Reflexiones y Propuestas en Educación Matemática. San Martín de Porres: Editorial Moshera S.R.L., 2014.

MORAN, J. Mudando a educação com metodologias ativas. In: SOUZA, C. A.; MORALES, O. E. T. (Orgs.). Convergências Midiáticas, Educação e Cidadania: aproximações jovens. Coleção Mídias Contemporâneas, v. II. Ponta Grossa: Foca FotoPROEX/UEPG, p. 15-33, 2015.

MOREIRA, M. A. Abandono da narrativa, ensino centrado no aluno e aprender a aprender criticamente. Ensino, Saúde e Ambiente, Niterói, RJ, v. 4, n. 1, p. 2-7, abr. 2011. Disponível em: https://periodicos.uff.br/ensinosaudeambiente backup/article/view/14592/9196.

Torrance, E. P. Torrance tests of creative thinking. Princeton: Personnel Pres. Inc., 1966. 